\title{
The Biosynthesis of 5-Hydroxytryptamine in Brain
}

\author{
By D. G. GRAHAME-SMITH \\ Department of Chemical Pathology and the Medical Unit, \\ St Mary's Hospital, London, W. 2
}

(Received 6 February 1967)

\begin{abstract}
1. Studies on the anatomical distribution of tryptophan 5-hydroxylase in dog brain show that the activity of this enzyme parallels the activity of 5-hydroxytryptophan decarboxylase and the concentration of 5-hydroxytryptamine in various areas of the brain. 2. Subcellular fractionation of homogenates of rabbit hind-brain has shown that at least $40 \%$ of the tryptophan 5-hydroxylase activity is associated with the crude mitochondrial fraction; equilibrium centrifugation in a discontinuous sucrose gradient suggests that this particulate tryptophan 5-hydroxylase is localized in the synaptosomes (nerve-ending particles). 3. Attempts to increase the activity of tryptophan 5-hydroxylase in iso-osmotic homogenates of brain by adding 5,6,7,8-tetrahydro-6,7-dimethylpteridine failed. 4. Procedures designed to rupture synaptosomes caused a fall in the activity of tryptophan 5-hydroxylase, which fall was reversed by adding 5,6,7,8-tetrahydro6,7-dimethylpteridine. This suggested either that the intact synaptosome, in which the tryptophan 5-hydroxylase is localized, contained an optimum amount of the pteridine, or that the pteridine could not pass across the nerve-cell membrane. 5. Partial purification of tryptophan 5-hydroxylase from brain preparations by ammonium sulphate precipitation revealed that the enzyme was completely dependent on 5,6,7,8-tetrahydro-6,7-dimethylpteridine for activity.
\end{abstract}

The presence and distribution of $5 \mathrm{HT}^{*}$ within the brain was first studied by Amin, Crawford \& Gaddum (1954). Since then there has been much work and speculation on the role of this amine in central synaptic transmission (see Salmoiraghi, Costa \& Bloom, 1965). In a previous communication (Grahame-Smith, 1964a) it was reported that the first step in the biosynthesis of 5HT, the enzymic 5-hydroxylation of $\mathrm{L}$-tryptophan with the production of L-5HTP, occurred in isolated brain tissue, and this has been confirmed by several workers (Gal, 1965; Nakamura, Ichiyama \& Hayaishi, 1965; Green \& Sawyer, 1966). The present paper describes further studies on the anatomical distribution, partial purification, cofactor requirement and properties of tryptophan 5 -hydroxylase in brain. In addition, the subcellular localization of tryptophan 5-hydroxylase in brain has been investigated. The work of Whittaker and his colleagues (see Whittaker, 1963) has clearly shown that crude mitochondrial fractions prepared from brain homogenates contain particles that have the appearance of pinched-off presynaptic nerve

* Abbreviations: 5HT, 5-hydroxytryptamine; 5HTP, 5-hydroxytryptophan; $\mathrm{DMPH}_{4}, \quad 5,6,7,8$-tetrahydro-6,7dimethylpteridine hydrochloride; iproniazid, $N$-isonicotinoyl- $N$ '-isopropylhydrazine. endings, and these have been termed 'synaptosomes' (Whittaker, Michaelson \& Kirkland, 1964). The synaptosome fraction has been shown to contain acetylcholine (Whittaker, 1959), choline acetyltransferase (Hebb \& Whittaker, 1958), acetylcholinesterase (De Robertis, Arnaiz, Salganicoff, de Iraldi \& Zieher, 1963), substance $P$ (Ryall, 1964) and noradrenaline (Potter \& Axelrod, 1963). Particularly relevant to the investigations reported here is that the synaptosome has been shown to contain both 5HT (Michaelson \& Whittaker, 1963) and some 5HTP decarboxylase (Arnaiz \& De Robertis, 1964), and evidence is presented in the present paper to show that tryptophan 5-hydroxylase is also located within this particle. Part of this work has been previously presented to The Biochemical Society (GrahameSmith \& Moloney, 1965).

\section{MATERIALS AND METHODS}

\section{Materials}

DL-[3-14C]Tryptophan was obtained from The Radiochemical Centre, Amersham, Bucks. 3-Hydroxybenzyloxyamine was given by Dr D. Drain of Smith and Nephew Ltd., Ware, Herts., and DL-5HTP and iproniazid were given by Roche Products Ltd., Welwyn Garden City, Herts. 
$\mathrm{DMPH}_{4}$ was purchased from Calbiochem, Los Angeles, Calif., U.S.A.

\section{Assay of tryptophan 5-hydroxylase}

The method used was that described by Grahame-Smith $(1964 a, b)$ with certain modifications. Tissue preparations were incubated with $\mathrm{DL}-[3-14 \mathrm{C}]$ tryptophan with the addition of 3-hydroxybenzyloxyamine to inhibit the decarboxylation of any 5HTP produced (Drain, Horlington, Lazare \& Poulter, 1962). Incubations were carried out in tubes or flasks flushed with $\mathrm{O}_{2}$, stoppered and shaken in a metabolic shaker. At the end of the incubation, $4 \mu$ moles of DL$5 \mathrm{HTP}$ and $2 \mathrm{ml}$. of $5 \%(w / v)$ trichloroacetic acid were added and the denatured protein was removed by centrifugation. After the excess of trichloroacetic acid had been extracted with two $10 \mathrm{ml}$. volumes of peroxide-free ether, the $\mathrm{pH}$ of the solution was adjusted to 4 by the addition of $2 \mathrm{ml}$. of $2 \mathrm{M}$-sodium acetate buffer, pH4. Then $0.25 \mathrm{~g}$. of charcoal deactivated with $4 \%$ stearic acid (Asatoor \& Dalgliesh, 1956) was added and, after standing for 10-15 min. to allow absorption of the indoles by the charcoal, the suspension was poured into small glass columns $(1 \mathrm{~cm}$. diam.), the constricted ends of which had been tightly packed with glass wool. The charcoal, which was held back by the glass wool, was washed free of non-absorbed salts by slowly passing $20 \mathrm{ml}$. of water through the column, and the indoles were then eluted with $10 \mathrm{ml}$. of $\mathrm{N}$-acetic acid in $80 \%(v / v)$ ethanol. Of the added 5HTP $75-80 \%$ was recovered. The ethanolic eluate was then evaporated to dryness in a vacuum desiccator. When dry, the extract was dissolved in water and, in early experiments, subjected to two-dimensional ascending paper chromatography on Whatman 3MM paper in the following solvents (Jepson, 1955) : solvent 1, propan-2-ol-aq. ammonia (sp.gr. 0.88)water (20:1 :2, by vol.); solvent 2, butan-1-ol-acetic acidwater (12:3:5, by vol.). [For individual $R_{F}$ values of the relevant compounds and the appearance of the twodimensional ascending paper chromatograms see Jepson (1955).]

In later experiments, this initial chromatography was performed in one dimension only with solvent 2 above, this being sufficient to give a preliminary separation of 5HTP $\left(R_{p} 0.27\right)$ from tryptophan $\left(R_{F} 0.50\right)$ and 3-hydroxybenzyloxyamine $\left(R_{F} 0.80\right)$. The chromatograms were radioautographed for 2-5 days (Kodirex film; Kodak Ltd., Kirkby, Liverpool) and the radioautographs developed. The chromatograms were viewed in u.v. light $(365 \mathrm{~m} \mu)$ and compared with a standard chromatogram of 5HTP stained with Ehrlich's reagent (Jepson, 1955). The position of the 5HTP was located by comparison with the standard chromatogram and by its fluorescence, and compared with the corresponding area on the radioautogram.

The 5HTP was then eluted from the paper, and the eluate was evaporated to dryness, dissolved in $0.4 \mathrm{ml}$. of water and incubated at $37^{\circ}$ for $45 \mathrm{~min}$. in air with a preparation of aromatic L-amino acid decarboxylase, partially purified from guinea-pig kidney to stage 3 of the procedure described by Clark, Weissbach \& Udenfriend (1954), which had been preincubated for $5 \mathrm{~min}$. with iproniazid (5.5 mM) (a monoamine oxidase inhibitor), pyridoxal phosphate (0.04 mM) and potassium phosphate buffer, $\mathrm{pH} 7 \cdot 4$ (50 $\mathrm{mm})$. The total volume of the incubation mixture was $0.8 \mathrm{ml}$. After incubation, $4 \mathrm{vol}$. of aq. $95 \%(\nabla / v)$ ethanol was added, the protein precipitate was removed by centrifugation and the protein-free extract was evaporated to dryness in a vacuum desiccator. The dry extract was then dissolved in $0.1 \mathrm{ml}$. of water and subjected either to two-dimensional ascending paper chromatography in the solvents described above or to one-dimensional ascending paper chromatography in solvent 2. The final chromatograms were radioautographed and also viewed in u.v. light $(365 \mathrm{~m} \mu)$ and compared with a standard chromatogram of 5HT stained with Ehrlich's reagent. The position of 5HT was located and this area was compared with the appearance of the radioautograph. The 5HT was then eluted from the paper, and the eluate dried and dissolved in $0.5 \mathrm{ml}$. of water. A portion $(0.25 \mathrm{ml}$.) was assayed for 5HT by the $\alpha$-nitroso- $\beta$-naphthol colorimetric procedure (Udenfriend, Weissbach \& Brodie, 1958), with suitable volumetric adjustment of the reagents, and $0.1 \mathrm{ml}$. was dried on an aluminium planchet for the estimation of radioactivity at infinite thinness in a gas-flow counter (Nuclear-Chicago model D47, efficiency $30 \%$ ). From the specific activity of the 5HT recovered and a knowledge of the amounts of 5HTP added as a carrier, it was possible to calculate the amount of L-tryptophan 5hydroxylated (Grahame-Smith, 1964a,b).

In all experiments, boiled tissue samples were identically incubated and assayed to assess the amount of non-enzymic tryptophan 5-hydroxylation (Grahame-Smith, 1964a), which has always been subtracted in the results presented below.

\section{Preparation of tissue}

Rabbit hind-brain. Rabbits were killed by a blow on the neck. The brain minus the olfactory lobes was removed intact. The cerebral cortex was then removed by cutting through the cerebral peduncles, and the cerebellum by severing its connexions with the brain-stem close to the surface of the latter. The portion left is referred to as the rabbit hind-brain. This was weighed and homogenized in the appropriate volume of the medium in a thick-walled glass tube with a Teflon pestle (the diameter of which was $0.2 \mathrm{~mm}$. less than that of the tube) revolving at $1240 \mathrm{rev}$./ min. Usually 12 passes of the pestle were made. All preparations were carried out at $4^{\circ}$.

Sections of dog brain. Studies on the anatomical distribution of tryptophan 5-hydroxylase in brain were carried out on dog brain. A mongrel puppy was anaesthetized with intravenous pentobarbitone, and the carotid arteries were cut. The brain was removed intact and the cerebrum and cerebellum were dissected away as described above. Sections were then made of the remaining part of the brain just anterior to the cephalic border of the pons and just distal to the caudal border of the medulla, creating two sections which are called here 'hypothalamus-thalamus' and 'mid-brain-pons-medulla' respectively. Homogenates $(1: 2, w / v)$ of the cerebrum, cerebellum and these two sections were made in Ringer phosphate solution (Krebs \& Henseleit, 1933).

\section{Subcellular fractionation of tryptophan 5-hydroxylase from rabbit hind-brain}

Preparation of fractions. Homogenates of rabbit hindbrain $(1: 8, w / v)$ were made in $0.32 \mathrm{M}$-sucrose containing 1 mM-mercaptoethanol. The subcellular fractionation procedure was carried out as described by Gray \& Whittaker 


\section{Homogenate}

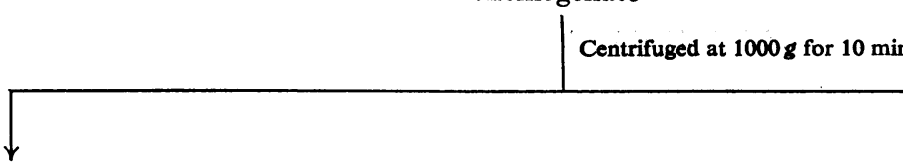

$1000 \mathrm{~g}$ particulate fraction, resuspended in $5 \mathrm{ml}$. of sucrose medium

Centrifuged at $1000 \mathrm{~g}$ for $10 \mathrm{~min}$.

$1000 \mathrm{~g}$ particulate fraction, resuspended in $5 \mathrm{ml}$. of sucrose medium

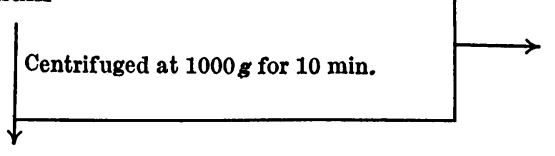

supernatants pooled

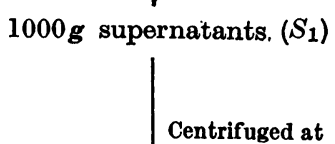

$1000 \mathrm{~g}$ particulate fraction $\left(P_{1}\right)$

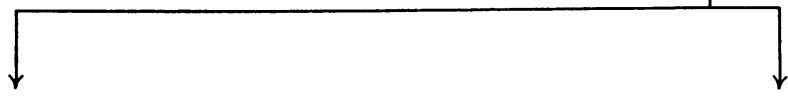

$17000 \mathrm{~g}$ particulate fraction

( $P_{2}$; crude mitochondrial fraction),

resuspended in $0.32 \mathrm{M}$-sucrose-

lmM-mercaptoethanol

Centrifuged at

$53500 \mathrm{~g}$ for $2 \mathrm{hr}$. into a

discontinuous gradient

of $0.8 \mathrm{M}$ - and $1.2 \mathrm{M}$-sucrose

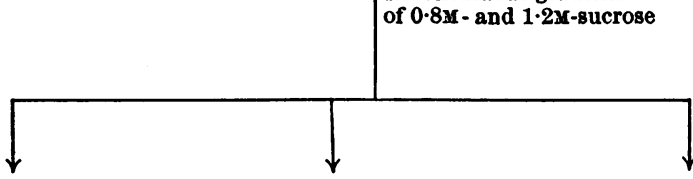

$A$ (myelin fraction)

$B$ (synaptosome fraction)

$C$ (mitochondrial fraction)
$17000 \mathrm{~g}$ supernatant $\left(S_{2}\right)$

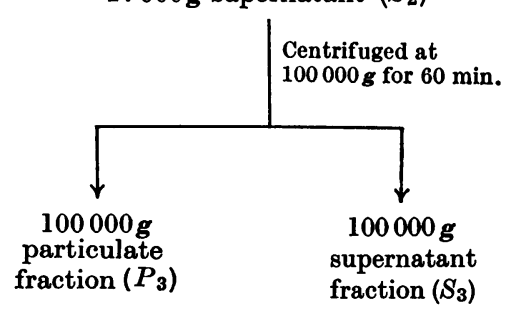

Scheme 1. Subcellular fractionation of rabbit hind-brain. Homogenate of rabbit hind-brain $(1: 8$, w/v) in 0.32 M-sucrose-1 mM-mercaptoethanol was the starting material.

(1962) (Scheme 1). All particulate fractions were resuspended in $0.32 \mathrm{M}$-sucrose containing 1 mM-mercaptoethanol. Fraction $\boldsymbol{P}_{2}$ ('crude mitochondrial' fraction) was resuspended in $17 \mathrm{ml}$. of this medium, and $5 \mathrm{ml}$. portions were layered on top of $10 \mathrm{ml}$. of $0.8 \mathrm{M}$-sucrose that $\frac{1}{2}-1 \mathrm{hr}$. before had been layered on top of $10 \mathrm{ml}$. of $1.2 \mathrm{M}$-sucrose. The Lusteroid tubes in which this gradient was made were centrifuged at $53500 \mathrm{~g}$ for $2 \mathrm{hr}$. in a swing-out head (SW 25.1) in an ultracentrifuge (Beckman-Spinco model $\mathrm{L}$ ). The gradient produced three fractions. Fraction $A$ ('myelin' fraction) lay at the interface of the $0.32 \mathrm{M}$-sucrose with the 0.8 M-sucrose; fraction $B$ ('synaptosome' fraction) lay at the interface of the $0.8 \mathrm{M}$-sucrose with the $1.2 \mathrm{M}$-sucrose; fraction $C$ ('mitochondrial' fraction) was a tan pellet at the bottom of the tube. The appearance of the tubes was as that described by Gray \& Whittaker (1962) for cerebral cortex. Each fraction was removed from the tube, either with a Pasteur pipette or by cutting the tube, and resuspended in the opalescent medium above it. All these procedures were carried out at $4^{\circ}$.

Portions ( $1 \mathrm{ml}$.) of each fraction were incubated with $155 \mathrm{~m} \mu$ moles of $\mathrm{DL}-\left[3-{ }^{14} \mathrm{C}\right]$ tryptophan (specific activity $31 \mu \mathrm{c} / \mu \mathrm{mole}), 3$-hydroxybenzyloxyamine $(1.5 \mathrm{~mm})$ and potassium phosphate buffer, $\mathrm{pH} 7.4$ (77 mM). The total volume of the incubation samples was $1.3 \mathrm{ml}$. Incubations were carried out for $1 \mathrm{hr}$. at $37^{\circ}$ under $\mathrm{O}_{2}$, after which the amount of 5HTP produced was assayed.

Analytical methods. The concentration of protein in each fraction was estimated by the method of Lowry, Rosebrough, Farr \& Randall (1951), with a bovine serum Bioch. 1967, 105 
albumin solution as a standard. Lactate dehydrogenase was used as a cytoplasmic marker (Johnson \& Whittaker, 1963), and was assayed by the method of Kornberg (1955). Succinate dehydrogenase was used as a mitochondrial marker (Whittaker, 1959), and was assayed as succinatetetrazolium reductase (Pennington, 1961).

Morphology of fractions. Electron-microscopic examination of fractions $A, B$ and $C$ were carried out by Dr V. P. Whittaker by both the negative staining technique (Horne \& Whittaker, 1962) and tissue sectioning after permanganate fixation and Araldite embedding.

\section{Partial purification of tryptophan 5-hydroxylase from brain}

Two rabbit hind-brains were homogenized in $0.32 \mathrm{M}$ sucrose containing $1 \mathrm{~mm}$-mercaptoethanol $(1: 3, \mathrm{w} / \mathrm{v})$. The homogenate was centrifuged at $100000 \mathrm{~g}$ for $60 \mathrm{~min}$. The particulate material was resuspended in the sucrose medium. $\left(\mathrm{NH}_{4}\right)_{2} \mathrm{SO}_{4}$ was added to the supernatant material to give $50 \%$ saturation (Dixon, 1953), and this solution was kept at $4^{\circ}$ for $20 \mathrm{~min}$., after which it was centrifuged at $15000 \mathrm{~g}$ for $30 \mathrm{~min}$. The $\left(\mathrm{NH}_{4}\right)_{2} \mathrm{SO}_{4}$ precipitate was dissolved in $10 \mathrm{ml}$. of $10 \mathrm{~mm}$-potassium phosphate buffer, $\mathrm{pH} 7 \cdot 4$, containing $1 \mathrm{~mm}$-mercaptoethanol.

Samples (1 ml.) of each preparation were incubated with $151 \mathrm{~m} \mu$ moles of $\mathrm{DL}-\left[3-{ }^{14} \mathrm{C}\right]$ tryptophan (specific activity $30 \cdot 2 \mu \mathrm{c} / \mu \mathrm{mole}), 3$-hydroxybenzyloxyamine $(1.5 \mathrm{~mm})$ and potassium phosphate buffer, pH7.4 (77 mM). The total volume of the incubation sample was $1.3 \mathrm{ml}$. $\mathrm{DMPH}_{4}$ was added as indicated in Table 4. Incubations were carried out for $1 \mathrm{hr}$. at $37^{\circ}$ under $\mathrm{O}_{2}$, after which the 5HTP produced was assayed.

\section{Disruption of synaptosomes}

Hypo-osmotic treatment (Johnson \& Whittaker, 1963). A rabbit hind-brain was homogenized in $10 \mathrm{~mm}$-potassium phosphate buffer, $\mathrm{pH}$, and the homogenate kept for 20 min. at $5^{\circ}$.

Ether treatment (Feldberg, 1945). To a portion of the above preparation was added peroxide-free ether $(0.8 \mathrm{ml}$. of ether $/ \mathrm{ml}$. of homogenate). The mixture was gently shaken for $3 \mathrm{~min}$. and kept at $5^{\circ}$ for $10 \mathrm{~min}$., after which air was bubbled through the mixture for $1 \mathrm{~min}$. to remove the ether.

\section{RESULTS} Anatomical distribution of tryptophan 5-hydroxylase
in brain

Portions ( $3 \mathrm{ml}$.) of homogenates of the various parts of a dog brain prepared as described in the Materials and Methods section were incubated with $315 \mathrm{~m} \mu$ moles of DL-[3-14C]tryptophan (specific activity $31.5 \mu \mathrm{c} / \mu \mathrm{mole}$ ) and 3-hydroxybenzyloxyamine $(1.5 \mathrm{~mm})$ in a total volume of $3.8 \mathrm{ml}$. Incubations were carried out for $1 \mathrm{hr}$. at $37^{\circ}$ in an atmosphere of oxygen. The amount of 5HTP produced was then assayed.

The results are shown in Table 1, where the tryptophan 5-hydroxylase activity is compared
Table 1. Anatomical distribution of 5HT, 5HTP decarboxylase and tryptophan 5-hydroxylase in dog brain

The distributions are expressed as percentages of the hypothalamus or hypothalamus-thalamus concentrations. In the first column, which data are from Bogdanski \& Udenfriend (1956), $100 \%$ is $10 \mathrm{~m} \mu$ moles of $5 \mathrm{HT} / \mathrm{g}$. of tissue. In the second column, which data are from Udenfriend (1958) and Udenfriend, Weissbach \& Bogdanski (1957), $100 \%$ is $665 \mathrm{~m} \mu \mathrm{moles}$ of $5 \mathrm{HT}$ formed/hr./g. of tissue. In the third column $100 \%$ is $0.685 \mathrm{~m} \mu$ mole of $5 \mathrm{HTP}$ formed/hr./g. of tissue.

5HTP Tryptophan 5HT decarboxylase 5-hydroxylase

Hypothalamus

Thalamus

Mid-brain

Pons

Medulla

Cortex (grey matter)

Cortex (white matter)

Cerebellum

\begin{tabular}{|c|c|}
\hline 100 & $100\}$ \\
\hline 37 & $32\}$ \\
\hline 55 & $83\}$ \\
\hline 23 & 24 \\
\hline 31 & 27 \\
\hline 19 & 6 \\
\hline 4 & - \\
\hline 4 & 3 \\
\hline
\end{tabular}

with the 5HTP decarboxylase activity and the $5 \mathrm{HT}$ content of similar areas of the brain found by other workers. Tryptophan 5-hydroxylase could not be detected in the cerebral cortex. The total activity of the 'hypothalamus-thalamus' section was $9.55 \mathrm{~m} \mu$ moles of $5 \mathrm{HTP}$ produced/hr., and that of the 'mid-brain-pons-medulla' section only $1.34 \mathrm{~m} \mu$ moles of 5HTP produced/hr. This emphasizes the high 5HT-biosynthetic activity of the former section, which is probably a reflection of activity in the hypothalamus, where 5HT is found in a very high concentration. Similar studies on rabbit brain revealed the tryptophan 5 -hydroxylase activity to be mainly localized in the hind-brain (as defined in the Materials and Methods section), and for this reason the rabbit hind-brain has been used in the studies described below.

\section{Time-course of tryptophan 5-hydroxylation in brain}

A portion ( $7 \mathrm{ml}$.) of a homogenate of rabbit hindbrain in Ringer phosphate solution $(1: 2, \mathrm{w} / \mathrm{v})$ was incubated with $632 \mathrm{~m} \mu$ moles of $\mathrm{DL}-\left[3-{ }^{14} \mathrm{C}\right]$ tryptophan (specific activity $31.5 \mu \mathrm{c} / \mu \mathrm{mole}$ ) and 3hydroxybenzyloxyamine $(2.5 \mathrm{~mm})$ at $37^{\circ}$ under oxygen. At certain times, $1 \mathrm{ml}$. portions of the incubation mixture were removed and assayed for the amount of 5HTP produced. The time-course of tryptophan 5-hydroxylation is shown in Fig. 1.

\section{Subcellular distribution of tryptophan 5-hydroxylase in rabbit hind-brain}

Initial experiments, in which homogenates of rabbit hind-brain made in Ringer phosphate 
solution were separated into total particulate and supernatant fractions by centrifugation at $100000 \mathrm{~g}$ for $60 \mathrm{~min}$., showed that most of the tryptophan 5-hydroxylase activity resided in the particulate matter. More searching fractionation was initially hindered by the unexplained disappearance of tryptophan 5-hydroxylation when homogenates were made in 0.32 M-sucrose. A similar phenomenon was described for tyrosine hydroxylase by Nagatsu, Levitt \& Udenfriend (1964); this was overcome by adding mercaptoethanol to the sucrose media. It was found that the addition of $1 \mathrm{~mm}$-mercaptoethanol to sucrose media also restored tryptophan

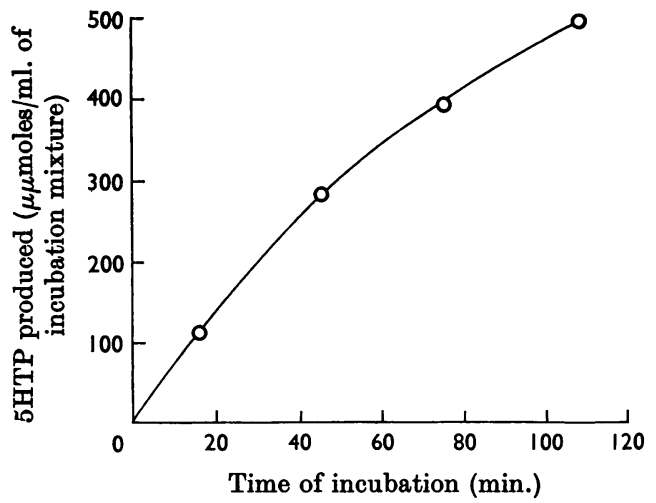

Fig. 1. Time-course of tryptophan 5-hydroxylation in a homogenate of rabbit hind-brain. For experimental details see the text. 5-hydroxylase activity, allowing more detailed subcellular fractionation. The results of two experiments carried out according to Scheme 1 are shown in Table 2. In Expt. 1, only tryptophan 5-hydroxylase activity was determined. In Expt. 2, tryptophan 5-hydroxylase, lactate dehydrogenase and succinate dehydrogenase activities were studied, and the morphology of fractions $A, B$ and $C$ was examined by electron microscopy. The results are expressed in two ways: first, as a percentage of the total activity recovered in the fraction; secondly, as the relative specific activity, i.e. percentage of the total activity recovered in the fraction/percentage of the total protein recovered in the fraction. The absolute recoveries of the various factors under study are shown in the caption to Table 2.

Homogenate and fractions $\mathrm{P}_{1}$ and $\mathrm{S}_{1}$. The amount of tryptophan 5-hydroxylase activity in fraction $S_{1}$ was found to depend greatly on the number of times fraction $P_{1}$ was washed, but under the conditions reported here $83-85 \%$ of the activity was in fraction $S_{1}$ and $15-17 \%$ in fraction $P_{2}$. This distribution was mimicked by lactate dehydrogenase, the cytoplasmic marker, but not by succinate dehydrogenase, the mitochondrial marker.

Fractions $\mathrm{S}_{1}, \mathrm{P}_{2}$ and $\mathrm{S}_{2}$. Tryptophan 5-hydroxylase activity appears to be fairly evenly distributed between fractions $P_{2}$ and $S_{2}$. Lactate dehydrogenase activity lies mainly in fraction $S_{\mathbf{2}}$ but $24 \%$ lies in fraction $P_{2}$, indicating the presence of entrapped cytoplasm within the synaptosomes. The higher relative specific activity $(0.88$ and 1.26$)$

Table 2. Distribution of tryptophan 5-hydroxylase, lactate dehydrogenase and succinate dehydrogenase in subcellular fractions of rabbit hind-brain

Recoveries of factors from homogenates in fractions $P_{1}+P_{2}+S_{2}$ were: tryptophan 5-hydroxylase, $102 \%$; lactate dehydrogenase, $67 \%$; succinate dehydrogenase, $97 \%$; protein, $119 \%$. Recoveries of factors from fraction $P_{2}$ in fractions $A+B+C$ were: tryptophan 5 -hydroxylase, $188 \%$; lactate dehydrogenase, $74 \%$; succinate dehydrogenase, 94\%; protein, 89\%. Tryptophan 5-hydroxylase activities in homogenates were: Expt. 1, 4.65 m $\mu$ moles of 5HTP produced/g. of hind-brain/hr.; Expt. 2, 1.23 m $\mu$ moles of 5HTP produced/g. of hind-brain/hr.

Distribution of recovered enzyme activities (\%)

\begin{tabular}{|c|c|c|c|c|c|c|c|c|c|}
\hline & & & & & & & & & \\
\hline & & $\begin{array}{l}\text { Tryp } \\
\text { 5-hyd }\end{array}$ & $\begin{array}{l}\text { phan } \\
\text { xylase }\end{array}$ & $\begin{array}{l}\text { Lactate } \\
\text { dehydro- }\end{array}$ & $\begin{array}{l}\text { Succinate } \\
\text { dehydro- }\end{array}$ & $\begin{array}{l}\text { Tryp } \\
\text { 5-hyd }\end{array}$ & $\begin{array}{l}\text { phan } \\
\text { xylase }\end{array}$ & $\begin{array}{l}\text { Lactato } \\
\text { dehydro- }\end{array}$ & $\begin{array}{l}\text { Succinate } \\
\text { dehydro- }\end{array}$ \\
\hline fraction & Subfraction & Expt. 1 & Expt. 2 & Expt. 1 & Expt. 2 & Expt. 1 & Expt. 2 & Expt. 2 & Expt. 2 \\
\hline Homogenate & $P_{1}$ & 17 & 15 & 18 & 57 & $0 \cdot 2$ & $0 \cdot 3$ & $0 \cdot 36$ & $1 \cdot 16$ \\
\hline & $S_{1}$ & 83 & 85 & 82 & 43 & $5 \cdot 5$ & $1 \cdot 67$ & $1 \cdot 6$ & $0 \cdot 85$ \\
\hline$S_{1}$ & $P_{2}$ & 51 & 44 & 24 & 100 & $0 \cdot 88$ & $1 \cdot 26$ & 0.69 & $2 \cdot 86$ \\
\hline & $S_{2}$ & 49 & 56 & 76 & 0 & $1 \cdot 2$ & $0 \cdot 86$ & $1 \cdot 17$ & 0 \\
\hline$P_{2}$ & $A$ & 43 & 38 & 22 & 6 & 0.83 & 0.93 & 0.54 & $0 \cdot 16$ \\
\hline & $\boldsymbol{B}$ & 48 & 44 & 45 & 10 & $1 \cdot 7$ & $1 \cdot 57$ & $1 \cdot 61$ & $0 \cdot 34$ \\
\hline & $C$ & 9 & 18 & 33 & 84 & $0 \cdot 47$ & 0.58 & $1 \cdot 06$ & $2 \cdot 7$ \\
\hline $\boldsymbol{s}_{2}$ & $P_{3}$ & - & 7 & - & - & 一 & $0 \cdot 28$ & - & - \\
\hline & $s_{3}$ & 一 & 93 & - & - & 一 & $1 \cdot 27$ & - & - \\
\hline
\end{tabular}


of tryptophan 5-hydroxylase in fraction $P_{2}$ as compared with that of lactate dehydrogenase $(0 \cdot 69)$ would seem to indicate a relative concentration of tryptophan 5-hydroxylase within the entrapped cytoplasm of fraction $P_{2}$. The striking difference between the distribution of tryptophan 5-hydroxylase activity and that of succinate dehydrogenase activity in these two fractions is strong evidence against a mitochondrial location for tryptophan 5-hydroxylase.

Fractions $\mathrm{P}_{2}, \mathrm{~A}, \mathrm{~B}$ and $\mathrm{C}$. Fraction $A$ (the 'myelin' fraction) contains 38 and $43 \%$ of the tryptophan 5-hydroxylase activity; fraction $B$ (the 'synaptosome' fraction) 44 and $48 \%$; fraction $C$ (the 'mitochondrial' fraction) 9 and $18 \%$. Although the activity of the 'synaptosome' fraction, on this basis, is highest, it is far the most active fraction on the basis of its relative specific activity. The close association in these three fractions between tryptophan 5-hydroxylase and lactate dehydrogenase, both in distribution and in relative specific activity, is striking. Equally striking is the dissociation between tryptophan 5-hydroxylase and succinate dehydrogenase, the mitochondrial marker.

Fractions $\mathrm{S}_{2}, \mathrm{P}_{3}$ and $\mathrm{S}_{3}$. In the one experiment in which fractions $P_{3}$ and $S_{3}$ were studied, tryptophan 5 -hydroxylase activity was clearly localized in fraction $S_{3}$, and fraction $P_{3}$ (the 'microsomal' fraction) contained very little.

Electron-microscopic studies. These studies were carried out in one experiment only (Expt. 2, Table 2 ) to see whether fractions $A, B$ and $C$ prepared from hind-brain showed any marked differences from similar fractions prepared from cerebral cortex and studied by Gray \& Whittaker (1962). The only difference observed was the presence of a few large synaptosomes among predominating mitochondria in fraction $C$. The correlation between lactate dehydrogenase and succinate dehydrogenase activities and the electron-microscopic appearances of fractions $A, B$ and $C$ prepared from the crude mitochondrial fraction $\boldsymbol{P}_{\mathbf{2}}$ confirmed that, as with cerebral cortical tissue, fraction $A$ consists mainly of myelin fragments, fraction $B$ of synaptosomes, and fraction $C$ of mitochondria.

These studies have shown that a significant proportion of the tryptophan 5-hydroxylase activity in hind-brain is located in the crude mitochondrial fraction $\left(P_{2}\right)$, and further fractionation of this material on a discontinuous sucrose gradient suggests that the activity is associated with the synaptosomes. Gal, Armstrong \& Ginsberg (1966) have also reported that brain tryptophan 5hydroxylase is located in the crude mitochondrial fraction.

Although these experiments indicate that about $40 \%$ of the tryptophan 5-hydroxylase activity in hind-brain is associated with the crude mito- chondrial fraction $\left(P_{2}\right)$, other experiments have suggested that the amount so associated may depend on the method of preparation of the initial homogenate. For instance, in homogenates made in Ringer phosphate solution $(1: 1, \mathrm{w} / \mathrm{v})$, no tryptophan 5-hydroxylase activity was found in a $100000 \mathrm{~g}-60 \mathrm{~min}$. supernatant fraction. However, when homogenates were made in $0.32 \mathrm{M}$-sucrose containing $1 \mathrm{~mm}$-mercaptoethanol, at a dilution of $1: 3(\mathrm{w} / \mathrm{v})$, then about $25 \%$ of the activity resided in the supernatant material; at a dilution of $1: 8$, the figure was $40 \%$.

Cofactor requirement and partial purification of tryptophan 5-hydroxylase in rabbit hind-brain

The cofactor required for full activity of phenylalanine 4-hydroxylase (Kaufman, 1959), tyrosine hydroxylase (Nagatsu et al. 1964) and carcinoid tumour tryptophan 5-hydroxylase (GrahameSmith, 1966) has been shown to be a tetrahydropteridine. For this reason the effect of $\mathrm{DMPH}_{4}$ on tryptophan 5-hydroxylation by brain homogenates made in iso-osmotic media was studied. On no occasion did $\mathrm{DMPH}_{4}$ increase tryptophan 5-hydroxylase activity in iso-osmotic homogenates, nor did the addition of $\mathrm{Fe}^{2+}$, mercaptoethanol or NADPH have any effect (Nagatsu et al. 1964). The results of such an experiment (Table 3) indicate the lack of any effect of $\mathrm{DMPH}_{4}$ on tryptophan 5hydroxylase activity in an iso-osmotic homogenate of brain ('untreated homogenate'). However, these experiments were carried out with concentrated homogenates (1:1-1:3, w/v) in iso-osmotic media, and under such conditions most of the tryptophan 5-hydroxylase activity would be localized within the synaptosomes. If so, the enzyme might be surrounded by an optimum concentration of tetrahydropteridine or occluded from added exogenous tetrahydropteridine by the membrane of the particle. Disruption of the synaptosome should then release tryptophan 5-hydroxylase and the pteridine cofactor, dilute both and perhaps decrease the activity of the preparation. Addition of the tetrahydropteridine to the preparation should then restore activity. To test this hypothesis, hypoosmotic 'shock' (Johnson \& Whittaker, 1963) or ether treatment (Feldberg, 1945) was used to disrupt the synaptosomes as described in the Materials and Methods section. The effect of $\mathrm{DMPH}_{4}$ on the tryptophan 5-hydroxylase activity of these preparations was then studied. The results are shown in Table 3. Although the hypoosmotically 'shocked' and ether-treated homogenates to which no $\mathrm{DMPH}_{4}$ was added have no activity, this is probably due to the omission of mercaptoethanol, which, as Huennekens, Matthews \& Scrimgeour (1963) have shown, stabilizes tetra- 
hydropteridines. However, Table 3 shows that the tryptophan 5-hydroxylase activity that is lost after hypo-osmotic 'shock' or ether treatment is restored by the addition of $\mathrm{DMPH}_{4}$.

It appears that, under conditions in which synaptosomes are intact, $\mathrm{DMPH}_{4}$ does not stimulate tryptophan 5-hydroxylase activity. After treatment calculated to disrupt the synaptosomes, there is a fall in the tryptophan 5-hydroxylase activity, which fall is reversed by the addition of $\mathrm{DMPH}_{4}$. These findings are compatible with the hypothesis that tryptophan 5-hydroxylase is situated within

Table 3. Effects of various treatments of brain homogenates on tryptophan 5-hydroxylase activity and the influence of $\mathrm{DMPH}_{4}$

Homogenates were prepared as described in the Materials and Methods section. A $1 \mathrm{ml}$. portion of each preparation was incubated at $37^{\circ}$ under $\mathrm{O}_{2}$ for $1 \mathrm{hr}$. with DL-[3-14 $\mathrm{C}$ ]tryptophan (15l m $\mu$ moles; specific activity $31 \mu \mathrm{c} / \mu \mathrm{mole}$ ), 3-hydroxybenzyloxyamine (1.5 mM) and potassium phosphate buffer, pH 7 (33 mM). When $\mathrm{DMPH}_{4}$ was added, its final concentration was $3.54 \mathrm{~mm}$.

Activity ( $\mu \mu$ moles of $5 \mathrm{HTP}$ produced $/ \mathrm{hr} . / \mathrm{ml}$.

Preparation

Untreated homogenate

Untreated homogenate

Hypo-osmotically 'shocked'

homogenate

Hypo-osmotically 'shocked'

homogenate

Ether-treated homogenate

Ether-treated homogenate the synaptosome where it is either surrounded by an optimum concentration of the pteridine cofactor or occluded from it by the membrane bounding the particle.

As these experiments suggested that a pteridine cofactor was required for the full activity of tryptophan 5-hydroxylase, partial purification of the enzyme was carried out in an attempt to dissociate it from its cofactor and see more clearly the effect of on enzyme activity adding back the supposed cofactor. The method of purification and the incubation conditions are described in the Materials and Methods section, and the results are shown in Table 4. Because $56 \%$ of the tryptophan 5-hydroxylase activity was trapped in the $100000 \mathrm{~g}$ particulate fraction, the yield and purification with respect to the homogenate were low, but with respect to the $100000 \mathrm{~g}$ supernatant fraction, from which the ammonium sulphate precipitate was actually prepared, the yield was $174 \%$ and the purification 10.5-fold.

The important points to emerge from this partial purification were the activity of the ammonium sulphate precipitate prepared from the $100000 \mathrm{~g}$ supernatant fraction in the presence of $\mathrm{DMPH}_{4}$ and the complete absence of activity when the pteridine was omitted. This stimulation of activity strongly suggests that a tetrahydropteridine acts as a cofactor in tryptophan 5-hydroxylation, as is the case for the other aromatic amino acid hydroxylations already discussed, and confirms the findings of Nakamura et al. (1965).

\section{DISCUSSION}

These studies further emphasize that tryptophan 5-hydroxylation, the first step in the biosynthesis of

Table 4. Partial purification of tryptophan 5-hydroxylase from rabbit hind-brain

\begin{tabular}{|c|c|c|c|c|c|c|c|c|}
\hline reparation & Addition & $\begin{array}{l}\text { Vol. } \\
\text { (ml.) }\end{array}$ & $\begin{array}{c}\text { Activity } \\
\text { ( } \mu \mu \text { moles of } \\
5 \mathrm{HTP} \\
\text { produced } \\
\text { ml./hr.) }\end{array}$ & $\begin{array}{c}\text { Total } \\
\text { activity } \\
\text { ( } \mu \mu \text { moles of } \\
\text { 5HTP } \\
\text { produced } \\
\text { by the total } \\
\text { fraction } / \mathrm{hr} .)\end{array}$ & $\begin{array}{l}\text { Protein } \\
\text { (mg./ml.) }\end{array}$ & $\begin{array}{c}\text { Specific } \\
\text { activity } \\
\text { ( } \mu \mu \text { moles of } \\
5 \mathrm{HTP} \\
\text { produced/ } \\
\text { mg. of } \\
\text { protein/hr.) }\end{array}$ & f & $\begin{array}{l}\text { Purification } \\
\text { factor }\end{array}$ \\
\hline & - & 28 & 288 & 8050 & 2.9 & 99.5 & 100 & 1 \\
\hline upernatant & - & 14 & 416 & 583 & $2 \cdot 6$ & 16 & $7 \cdot 25$ & $0 \cdot 16$ \\
\hline particulate & - & 20 & 226 & 4520 & $1 \cdot 2$ & 188 & 56 & 1.89 \\
\hline 4 supernatant & - & 20 & 0 & $\mathbf{0}$ & 0.2 & 0 & 0 & 0 \\
\hline 4 supernatant & $\mathrm{DMPH}_{4}$ & 20 & 0 & $\mathbf{0}$ & 0.2 & 0 & 0 & $\mathbf{0}$ \\
\hline recipitate & - & 10 & 0 & 0 & 0.6 & 0 & 0 & 0 \\
\hline precipitate & $\mathrm{DMPH}_{4}$ & 10 & 101 & 1010 & $0 \cdot 6$ & 168 & $\begin{array}{l}\text { (H) } 12 \cdot 5^{*} \\
\text { (S) } 174^{*}\end{array}$ & $\begin{array}{l}\text { (H) } 1.69^{*} \\
\text { (S) } 10.5^{*}\end{array}$ \\
\hline
\end{tabular}

* The yields and purifications of this fraction are expressed in two ways: with respect to the homogenate (H); with respect to the $100000 \mathrm{~g}$ supernatant (S). 
5HT, occurs in brain. Although no detailed kinetic studies of this reaction have been done during the work reported here, Green \& Sawyer (1966) found a maximal rate for tryptophan 5-hydroxylation in preparations of rabbit brain-stem of about $2 \mu \mathrm{g}$. of $5 \mathrm{HT}$ produced/g. of brain/hr., with an L-tryptophan concentration of $40 \mu \mathrm{M}$. In the present studies, the rate of tryptophan 5-hydroxylation was about $0.8 \mu \mathrm{g}$. of $5 \mathrm{HTP}$ produced/g. of rabbit hindbrain/hr., with an L-tryptophan concentration of $60 \mu \mathrm{M}$. However, the rates of decarboxylation of 5HTP in the brain are much higher. For instance, the hypothalamus of the dog will decarboxylate 5 HTP at the rate of $117 \mu \mathrm{g} . / \mathrm{g} . / \mathrm{hr}$. (Udenfriend, 1958). The much higher activity of this second enzyme in the pathway of biosynthesis of 5HT suggests that tryptophan 5-hydroxylation is enzymically the rate-limiting step, as it is in the biosynthesis of $5 \mathrm{HT}$ in carcinoid tumours (GrahameSmith, 1966).

The question arises whether the brain is independently capable of synthesizing all the 5HT it needs, or whether it is supplied with 5HTP or 5HT manufactured at some peripheral site. Gastrointestinal tissue (Cooper \& Melcer, 1961 ; GrahameSmith, 1966) and liver (Freedland, Wadzinski \& Waisman, 1961) have both been shown to synthesize 5HT. However, the removal of the gastrointestinal tract does not lower the $5 \mathrm{HT}$ concentration in brain (Bertaccini, 1960), and tryptophan 5hydroxylation in liver is carried out by the nonspecific action of phenylalanine 4-hydroxylase and can be inhibited in vivo by Amethopterin (methotrexate) without affecting the concentration of 5HT in the brain (Renson, Weissbach \& Udenfriend, 1962). Although brain 5HT concentration can be raised by administering 5HTP, differences exist between the distribution of $5 \mathrm{HT}$ increased in this way and that of $5 \mathrm{HT}$ increased within the brain by the administration of monoamine oxidase inhibitors (Green \& Sawyer, 1964). It is probable that in vivo in the rat the rate of $5 \mathbf{H T}$ biosynthesis is about $1 \mu \mathrm{g}$./g. of brain/hr. (Garrattini \& Valzelli, 1965), and in the present studies rates of $0.8 \mu \mathrm{g}$./g. of rabbit hind-brain/hr. have been observed. These rates in vivo and in vitro are comparable and suggest that sufficient of the rate-limiting enzyme, tryptophan 5 -hydroxylase, exists in the brain to account for the total biosynthesis of 5HT there. The close parallel between the distributions of tryptophan 5-hydroxylase, 5HTP decarboxylase and 5HT at both the anatomical and the subcellular level suggest that in the brain $5 \mathrm{HT}$ is synthesized at the site at which it is found. All these facts lead to the conclusion that the brain can synthesize all the $5 \mathrm{HT}$ it needs, at the sites at which it needs it, and does not rely on a peripheral source of 5HTP or $5 \mathrm{HT}$. Such a conclusion is pertinent in the search for quantitative abnormalities of 5HT biosynthesis and metabolism in psychiatric disease. Because the contribution that the brain makes to the total body synthesis of $5 \mathrm{HT}$ is probably less than $5 \%$, quantitatively small changes in the synthesis and metabolism of $5 \mathrm{HT}$ at discrete loci within the brain, though perhaps extremely important functionally, might be undetectable in a study of the total body synthesis of 5HT, unless extracerebral synthesis and metabolism is similarly affected, which may not necessarily be the case.

The localization of tryptophan 5-hydroxylase, 5HTP decarboxylase (Arnaiz \& De Robertis, 1964) and 5HT (Michaelson \& Whittaker, 1963) at the presynaptic nerve-ending is consistent with the hypothesis that 5HT may be concerned directly or indirectly with the chemical transmission of the nervous impulse in certain discrete areas of the brain. The finding that the more concentrated the initial homogenate of brain the more tryptophan 5-hydroxylase activity is found in the particulate matter on centrifugation suggests that some property of the more concentrated homogenate protects particles containing tryptophan 5-hydroxylase from rupture, and obviously under these conditions synaptosomes would be less liable to rupture than large nerve-cell bodies. Even so, it would be imprudent to suggest that the synaptosome was the sole site of localization of tryptophan 5-hydroxylase, for the activity seen in the highspeed supernatant fractions may reflect activity originally present in the cytoplasm of the nervecell body, where 5HT can be detected in low concentration by fluorescent microscopy (Dahlström \& Fuxe, 1964, 1965).

It is known that certain putative chemical transmitting substances or systems involved in their metabolism are localized in well-defined tracts and areas of the central nervous system (Dahlström \& Fuxe, 1964, 1965; Lewis, 1965), and that at the subcellular level the enzymes responsible for the biosynthesis of such substances seem to be partially localized in the presynaptic nerve endings, at least for 5HT and acetylcholine (De Robertis et al. 1963). This suggests that functional differentiation within the central nervous system may be dependent partially on having several synaptic chemical transmitting agents or regulators of synaptic transmission, each of which may serve an independent neuronal pathway to which other pathways dependent on other transmitter substances are insensitive.

The present studies have confirmed the work of Nakamura et al. (1965), who reported that a reduced pteridine is necessary for full activity of tryptophan 5-hydroxylase. The demonstration that tryptophan 5-hydroxylase is localized within the synaptosomes of an iso-osmotic brain homogenate, 
and that until the synaptosomes are disrupted no stimulatory effect of the reduced pteridine is observed, may explain why Gal et al. (1966) and Green \& Sawyer (1966) could find no stimulation of tryptophan 5-hydroxylation in iso-osmotic brain homogenates on the addition of a reduced pteridine. This situation is similar in some ways to that surrounding choline acetyltransferase.

Feldberg (1945) showed that ether treatment of brain homogenates activated choline acetyltransferase, and Hebb \& Smallman (1956) showed that choline acetyltransferase is present in iso-osmotic brain homogenates in an occluded form. Since then it has been shown that choline acetyltransferase is localized in the synaptosome fraction (Hebb \& Whittaker, 1958; De Robertis et al. 1963). One presumes that the ether activation of choline acetyltransferase is brought about by the rupture of the synaptosomes and the release of the choline acetyltransferase, thereby allowing substrates easier access to the enzyme and resulting in an increased rate of synthesis of acetylcholine.

In addition to tryptophan 5-hydroxylase, phenylalanine 4-hydroxylase (Kaufman, 1959) and tyrosine hydroxylase (Nagatsu et al. 1964) have also been shown to require a reduced pteridine for full activity. However, although phenylalanine hydroxylation by liver is inhibited by Amethopterin (Kaufman \& Lovenberg, 1959), tryptophan 5hydroxylation by brain (Grahame-Smith, 1964a) and carcinoid tumour (Grahame-Smith, 1964b) is not, pointing to some difference between these two reactions.

So far tryptophan 5-hydroxylase in brain seems to be specific for tryptophan, since brain tissue does not hydroxylate phenylalanine (Renson et al. 1962), and partially purified tryptophan 5-hydroxylase from brain does not hydroxylate tyrosine (Nakamura et al. 1965). It is probable that the specificity of action and localization of these enzymes within the brain are of crucial importance in determining whether a catecholamine or $5 \mathrm{HT}$ will be formed at a particular site. At certain sites tyrosine hydroxylase leads to the formation of catecholamines and at other sites tryptophan hydroxylase leads to the formation of 5HT. The decarboxylation of the aromatic amino acids within the brain does not appear to have such specificity, for the brain enzyme that catalyses this reaction acts on both L-dihydroxyphenylalanine and L-5HTP (Lovenberg, Weissbach \& Udenfriend, 1962).

I thank Professor W. S. Peart and Professor A. Neuberger for their advice and support during this work. I am extremely grateful to Dr V. P. Whittaker for carrying out the electron-microscopic studies on brain subcellular fractions. These studies were carried out during the author's receipt of research scholarships awarded by the Royal College of Physicians (London) and the Wellcome Trust.
Technical assistance was made possible by financial support from the Mental Health Research Fund. These studies form part of the work done in partial fulfilment of the requirements for the degree of Ph.D. in the University of London.

\section{REFERENCES}

Amin, A. H., Crawford, T. B. B. \& Gaddum, J. H. (1954). J. Physiol. 126, 596.

Arnaiz, G. R. de L. \& De Robertis, E. (1964). J. Neurochem. 11, 213.

Asatoor, A. \& Dalgliesh, C. E. (1956). J. chem. Soc. p. 2291. Bertaccini, G. (1960). J. Physiol. 153, 239.

Bogdanski, D. F. \& Udenfriend, S. (1956). J. Pharmacol. 116, 7.

Clark, C. T., Weissbach, H. \& Udenfriend, S. (1954). $J$. biol. Chem. 210, 139.

Cooper, J. R. \& Melcer, I. (1961). J. Pharmacol. 132, 265.

Dahlström, A. \& Fuxe, K. (1964). Acta physiol. scand. 62, Suppl. 232.

Dahlström, A. \& Fuxe, K. (1965). Acta physiol. scand. 64, Suppl. 247.

De Robertis, E., Arnaiz, G. R. de L., Salganicoff, L., de Iraldi, A. P. \& Zieher, L. M. (1963). J. Neurochem. 10, 225.

Dixon, M. (1953). Biochem. J. 54, 457.

Drain, D. J., Horlington, M., Lazare, R. \& Poulter, G. A. (1962). Life Sci.1, 93.

Feldberg, W. (1945). Physiol. Rev. 25, 596.

Freedland, R. A., Wadzinski, I. M. \& Waisman, H. A. (1961). Biochem. biophys. Res. Commun. 5, 94.

Gal, E. M. (1965). Fed. Proc. 24, 580.

Gal, E. M., Armstrong, J. C. \& Ginsberg, B. (1966). J. Neurochem. 13, 643.

Garattini, S. \& Valzelli, L. (1965). Serotonin, p. 205. London: Elsevier Publishing Co.

Grahame-Smith, D. G. (1964a). Biochem. biophys. Res. Commun. 16, 586.

Grahame-Smith, D. G. (1964b). Biochim. biophys. Acta, 86, 176.

Grahame-Smith, D. G. (1966). Ph.D. Thesis: University of London.

Grahame-Smith, D. G. \& Moloney, L. (1965). Biochem. $J$. 96, 66P.

Gray, E. G. \& Whittaker, V. P. (1962). J. Anat., Lond., 96, 79.

Green, H. \& Sawyer, J. L. (1964). In Progress in Brain Research, vol. 8, p. 150. Ed. by Himwich, H. E. \& Himwich, W. A. London: Elsevier Publishing Co.

Green, H. \& Sawyer, J. L. (1966). Analyt. Biochem. 15, 53. Hebb, C. O. \& Smallman, B. N. (1956). J. Physiol. 134, 385. Hebb, C. O. \& Whittaker, V. P. (1958). J. Physiol.142, 187. Horne, R. H. \& Whittaker, V. P. (1962). Z. Zellforsch. 58, 1. Huennekens, F. M., Matthews, C. K. \& Scrimgeour, K. G. (1963). In Methods in Enzymology, vol. 6, p. 804. Ed. by Colowick, S. P. \& Kaplan, N. O. New York: Academic Press Inc.

Jepson, J. B. (1955). Lancet, ii, 1009.

Johnson, M. K. \& Whittaker, V. P. (1963). Biochem. J. 88, 404.

Kaufman, S. (1959). J. biol. Chem. 234, 2677.

Kaufman, S. \& Lovenberg, B. (1959). J. biol. Chem. 234, 2683. 
Kornberg, A. (1955). In Methods in Enzymology, vol. 1, p. 441. Ed. by Colowick, S. P. \& Kaplan, N. O. New York: Academic Press Inc.

Krebs, H. A. \& Henseleit, K. (1933). Hoppe-Seyl. Z. 217, 193.

Lewis, P. R. (1965). Biochem. J. 96, 44 P.

Lovenberg, W., Weissbach, H. \& Udenfriend, S. (1962). J. biol. Chem. 237, 89.

Lowry, O. H., Rosebrough, N. J., Farr, A. L. \& Randall, R. J. (1951). J. biol. Chem. 193, 265.

Michaelson, I. A. \& Whittaker, V. P. (1963). Biochem. Pharmacol. 12, 203.

Nagatsu, T., Levitt, M. \& Udenfriend, S. (1964). J. biol. Chem. 239, 2910.

Nakamura, S., Ichiyama, A. \& Hayaishi, O. (1965). Fed. Proc. 24, 604.

Pennington, R. J. (1961). Biochem. J. 80, 649.
Potter, L. T. \& Axelrod, J. (1963). J. Pharmacol. 142, 291.

Renson, J., Weissbach, H. \& Udenfriend, S. (1962). J. biol. Chem. 237, 2261.

Ryall, R. W. (1964). J. Neurochem. 11, 131.

Salmoiraghi, G. C., Costa, E. \& Bloom, F. E. (1965). Annu. Rev. Pharmacol. 5, 213.

Udenfriend, S. (1958). In 5-Hydroxytryptamine, p. 45. Ed. by Lewis, G. P. London: Pergamon Press Ltd.

Udenfriend, S., Weissbach, H. \& Bogdanski, D. F. (1957). Hormones, Brain Function and Behavior, p. 147. New York: Academic Press Inc.

Udenfriend, S., Weissbach, H. \& Brodie, B. B. (1958). Meth. biochem. Anal. 6, 106.

Whittaker, V. P. (1959). Biochem. J. 72, 694.

Whittaker, V. P. (1963). Symp. biochem. Soc. $23,109$.

Whittaker, V. P., Michaelson, I. A. \& Kirkland, R. J. A. (1964). Biochem. J. 90, 293. 